\title{
Challenges and Difficulties Related to Implement Integrated IS Project in Morocco: ERP Projects in Public University Case Study
}

\author{
Issam Taqafi \\ SIAD Laboratory, Hassan \\ 1st University Settat, \\ Morocco
}

\author{
Mustapha \\ Belaissaoui \\ SIAD Laboratory, Hassan \\ 1st University Settat, \\ Morocco
}

\author{
Younous Elmrini \\ SIAD Laboratory, Hassan \\ 1st University Settat, \\ Morocco
}

\author{
Mouhsine Lakhdissi \\ FST, Hassan 1st \\ University Settat, Morocco
}

\begin{abstract}
To increase their performance for adopting ERP (Enterprise Resource Planning) in their Information Systems, many academic institutions around the world are attracted to ERP software packages, it is because they are expected to bring productivity and efficiency gains, particularly through their ability to make the organization more integrated. ERP solutions are very complex software packages. To improve the chance of success, they must be carefully evaluated and selected, needing a proper evaluation and analysis framework. This paper attempts to identify important issues affecting Enterprise Resource Planning (ERP) implementation in Moroccan context. The results presented are based on a case study (action research) in four large Moroccan public universities. This study concerns mainly the new implementation of an ERP. The problems addressed are spread over different phases of the implementation life cycle and discuss several aspects: scope, sponsoring, project management standard versus customizations, resistance to change / resisting forces, cultural aspects, operations and values system.
\end{abstract}

\section{Keywords}

Difficulties; challenges, Integrated IS, Morocco; Implementing; Performance; public university'

\section{INTRODUCTION}

The academic landscape all over the world is evolving in an increasingly complex and changing environment. Today, they confront several problems: The massification of education, the multiplication of rankings, the transformation of financing methods and, more generally, internationalization constitute some of the profound upheavals facing Higher Education institutions in most countries of the world. These upheavals have resulted in major reforms of universities in recent years, including the Moroccan public university, which is currently experiencing an era of profound changes: (a) Reforms of the sector of training and education since 2000 ((Training, pedagogical, Structuring research, Valorization, the advanced status granted by the European Union with the adoption of the Bologna Process 1999), (b) Generalization of ICTs, (c) Gradual strengthening of University Autonomy;

This situation has led to a proliferation of missions assigned to the Moroccan university and an obligation to adopting of a model based on the integrated management system. In addition, the introduction of this integrated management cannot be conceived without the establishment of an operational information system. According to Bidan [1], "integration aims at the cooperation of applications within a single system and for characteristic a unique logical database". Indeed, it is through the uniqueness of the database that the risks of incoherence and redundancy existing during the multiple data processing operations can be avoided and the various management processes subsequently harmonized; Integration therefore means both the homogenization and the coherence of the management information system [2], and presents two major operational characteristics, namely the uniqueness of the reference system and the homogeneity of the processes. It is from this perspective that the integrated information system such as the ERP system supports such orientations as a technology of integration.

To increase their performance for adopting ERP (Enterprise Resource Planning) in their Information Systems, many academic institutions around the world are attracted to ERP software packages, it is because they are expected to bring productivity and efficiency gains, particularly through their ability to make the organization more integrated.

ERP solutions are very complex software packages. To improve the chance of success, they must be carefully evaluated and selected, needing a proper evaluation and analysis framework.

After selecting the most appropriate solution, the adaptation and customization effort would be significant. Taking into consideration that most Moroccan universities are public universities, the financial effort of such an initiative would be very high for any of them. An ERP implementation is difficult both nationally and internationally and will probably be the most complex technology project ever undertaken on university, because of many considerations: cultural, employee's maturity, legal aspect, etc. Therefore, executives at university and university community must know as much about ERP systems and the ERP project as practical. Service for students should be a major priority with an ERP system implemented within the university. Currently, the greatest challenge for our universities is to manage complexity in a single systematic vision through an operational information system that is modeled and updated as technology evolves. This publication attempts to draw the main challenges in managing this kind of project.

\section{RESEARCH QUESTION}

Universities have often been described as "organized anarchy", as their rules and procedures are so cumbersome and their management is carried out by a large number of people, in a participatory way, with a strong desire for autonomy linked to the notion of academic freedom. This inefficient model is particularly challenged when the competition linked to globalization, the logic of external evaluation, the massification of lessons learned, the requirement for research results increase the pressure on all categories of staff and make them insecure. According to a report by the Moroccan CSEFRS [3], "One of the weaknesses that emerges from the evaluation of the application of the national charter on training and education is the lack of 
support for reforms by monitoring and regulatory mechanisms defining the mode of monitoring and evaluation. However, the monitoring of the implementation of the reforms recommended by the Charter has not been based on an operational integrated information system guaranteeing the feedback of information and data for proper monitoring and relevant decision-making. Indeed, it is difficult to talk about good governance without the availability of reliable and timely information. [3],, (Analytical report; implementation of the National Charter for Education and Training 2000-2013 (deficit and challenges). To face this main obstacle facing the Moroccan university, which is the difficulty of obtaining accurate data and information, it has embarked on a process of setting up a coherent integrated information system guaranteeing the uniqueness of information, through several projects to overcome the dysfunction of information feedback. Moving to integration technology, such as ERP software packages, is an experience with many challenges and risks. the ERP implementation projects can paralyze the academic institutions if they are not properly implemented. Horror stories are drawn in the case of failed implementations $[6,7]$. The difficulties faced by universities in implementing the ERP system are many [5], and it is therefore necessary to examine the factors that can lead to a successful implementation of the ERP system [4] (Pollock and Cornford, 2004). Indeed, numerous reports around the world describe unsuccessful ERP implementations. $70 \%$ of ERP implementations projects have not reached their expected benefits. Based on other studies, the percentage of failed ERP projects implementation varies between $40 \%$ and $60 \%$ and has sometimes led to a global collapse of the institutions. Practitioners tend to discuss the sources of failures of these implementations from different views: closed proprietary system, the bad utilization of the ERP, etc. Of course, these different failures depend on the size of the company, the nature of the activity, the project context, the country's culture, etc. $[6,8]$.

A review of the existing literature on ERP system implementation in the university context revealed that few studies were devoted to critical success factors that could influence the implementation of the ERP system in universities. For t3his reason, this article aims to answer the following research question:

What are the major difficulties and challenges to manage to avoid this failure risk? Especially in a Moroccan public universities context?

\section{LITERATURE REVIEW}

\subsection{University context}

A university's most valuable assets are faculty, students, and staff. Each has distinctive interests within the same organization. For faculty, a university is a place to teach, conduct research, and write. For students, it is a place to learn, live, and entertain. For staff, it may share many features with corporate work, including management structure, hours, and HR practices. [7],4], stated that university is "thought of as a band of scholars coming together in pursuit and dissemination of knowledge, governed by a more or less collegiate model of organization, based around a complex structure of committees and with a high degree of individual and departmental autonomy".

According to [9], universities have a certain combination of unique characteristics: complexity of purpose, limited measurability of outputs, both autonomy and dependency with regard to wider society, and diffuse structures of authority and internal fragmentation. This particular combination makes universities "unique", while general corporations have one or more of these components [4]
Considering the significant influence of information technology in universities, it is not surprising that many have adopted ERP systems for development and reengineering of administrative systems as a route to improved performance $[9,10]$.

\subsection{ERP Definition}

Enterprise resource planning (ERP) systems are integrated IS designed to create a seamless software applications link between all the processes of an organization and they support many, even most, aspects of a organization's information needs. Due to its business oriented vision, ERP systems are categorized as business applications. Technically, they are categorized as Commercial Off-The-Shelf (COTS) products.

(ERP) is information system software that aims to integrate all business processes and functions in a central database. This boosts the management of business resources (finance, production, human resource, materials, etc.) in an effective, efficient, and productive way [2] [3] [4] [5]. Moreover, the universities ERP system is defined as "an information technology solution that integrates and automates recruitment, admissions, financial aid, student records, and most academic and administrative services" [6].

According to [14,15] ERP system is designed to support both primary and support activities of a firm's value chain In short, a successfully implemented ERP system can results in improved performance, especially from the perspective of business administration and information management. Indeed, the ERP attempts to integrate all functions and business of an enterprise in a single and centralized information system to serve several needs of multiple business disciplines: finance, accounting, management control, human resources, maintenance, production, etc. Despite the great diversity of these needs, ERP combines them into a single database so that they can share information easily and communicate with each other.

ERP systems can help a company achieve competitive advantage. Enterprise systems provide value both by increasing operational efficiency and by providing firmwide information to help managers make better decisions [11,13] (Some of the important attributes of ERP are its abilities to: automate and integrate an organization's business processes; produce and access information in real time environment and share common data and practices across the entire enterprise. Most organizations expect ERP systems to reduce their operating cost, increase process efficiency, improve customer responsiveness and provide information for decision making [12]

Implementing an ERP system is not a simple task and takes a lot of planning and consulting. ERP implementation takes a lot of effort, time and money and if these are not handled properly they can become the reasons why ERP is not implemented successfully [16].

Another definition dictates that a new class of software emerged the IT market in the 90's. Usually called Enterprise Resource Planning (ERP), these complete software solutions seek to integrate all processes and functions of a company to present an overview from a single architecture [16].

Definitions of ERP are many and various. We retain in this article the one proposed by [17] which present the ERP as an information system "configurable, modular and integrated, leading to integrate and optimize enterprise management process by providing a single repository based on standards management rules". This definition highlights two main dimensions inherent in ERP solutions that distinguished them from other information systems: "Integrity" and "Settings".

These dimensions imply different characteristics: 
- Having one designer;

- Improving the quality of information by eliminating redundancies and ensuring the uniqueness of the information made available to the end user;

- The existence of different modules restrained in one centralized database;

- Continuous improvement and integration of changes in real-time;

- Facilitating both the audit and the control by providing traceability of the various transactions;

- Integration of different management functions (Human Resources Management, Management accounting, Logistics, etc.) making up the company information system.

The usage of ERP is not new; it started in the 1960s as accounting software named Inventory Control (IC), in the 1970s it was developed into Material Requirements Planning (MRP) which developed into planning and control of the production cycle. After that, in the 1980s, MRP was advanced in Manufacturing Resource Planning (MRP II) which used to increase the efficiency of manufacturing by technology integrations for information. Then, MRP II extended to ERP systems [5] [8] [9].

In the mid-90s, many efforts have been made to improve the ERP system by replacing the traditional database to reduce the response time. Then, the ERP was expanded with additional functions (order management, financial management, logistics, distribution, production, quality control, etc.).

Today, several studies on the ERP market present a new concept: the cloud ERP. It's completely in line of platforms like SaaS (Software as a Service), PaaS (Platform as a Service) and IaaS (Infrastructure as a Service).

\begin{tabular}{|c|c|}
\hline Year & Chronology \\
\hline 2009 & ERP Cloud \\
\hline $2000 \mathrm{~s}$ & Extend ERP \\
\hline $1990 \mathrm{~s}$ & ERP \\
\hline $1980 \mathrm{~s}$ & MRP II \\
\hline $1970 \mathrm{~s}$ & MRP \\
\hline
\end{tabular}

In the first part of this literature review, we tried to draw up

the history and the evolution of ERP around the world. In this second part, we'll discuss some researches addressing the difficulties encountered during ERP projects implementation. [18] assert that the difficulties of implementing ERPs are many: the top management commitment, the willingness of the company to conduct reengineering and accept full integration, the expert consultant's deficiency on some core business with changing demand, time and cost implementation's, the variety of suppliers, the willingness of employees, etc.

[19] say that several authors have dealt with difficulties of implementing ERP; however, few empirical studies have been conducted to validate this work. In their article, the main factors impeding the success of this kind of strategic project are respectively the adoption of project management principles, the feasibility of the project in the company, the support of top management, process reengineering, the consultant's service quality and time and costs project. [26].

[20] conducted a comparison on these issues between the developed and under development countries. They claimed that the difference comes from two broad categories of factors: "National / environmental" and "organizational / internal", each one includes five variables which are respectively: economic growth, infrastructure, industrial maturity, government regulation and the regional environment; then the maturity of information systems, computer education, company size, the commitment of senior management and experience in reengineering of business processes. They ultimately concluded that the existing difference between these factors places the developed countries in advance of those being in development.

\subsection{This ERP System benefits in organizations}

Comprehensive studies show that the benefits of implementing ERP for different organizations are very diverse. The most important benefits are as follow $[21,22,23]$

- Organizational integrity in information and increasing the consistency of organization's information.

- Standardization of organizational processes based on the best experiences of software provider companies.

- Reengineering organizational processes and reducing the time to do them.

- Converting processes from implicit mode to explicit mode by complete reengineering.

- Quick installation of ERP-related systems or special softwares of organization.

- Developing new systems and technologies with better possibilities and sufficient facilitation of related affairs.

- Changing the focus from mere computer programming to improve processes in the organization.

- Cooperative business and joint ventures, by integrating and changing the structure of sub- sectors by maintaining

\subsection{ERP System in university context}

A number of articles in the literature presented studies of ERP implementation in higher education. Literature reviews by [24 indicated that the number of such studies is limited.

The adoption of ERP system in the higher education sector can be traced back to 1980s, where the higher education institutions recognized the need for integrating different administrative duties and functions into a more cost-effective and systematic approach [21]. For decades, administrative activities such as scheduling, student administration, personnel management, facilities management, and financial systems have been supported by standalone legacy systems Integrating or merging these separate legacy system is often cited as "costly "difficult" [4], and "challenging" $[22,23,24,25]$

The modular and standalone nature of these legacy systems is quite problematic for the higher education institutions because they need to customize the system to fit with different and unique needs to support lecturers and students in several services for teaching, timetabling, examinations, etc. that are not part of traditional generic ERP [4] . Despite of the various difficulties associated with the implementation of ERP system in higher education institutions, the demand for a solution for integrating 
administrative duties in universities remains. In many universities in the united states, the ERP system are used for speeding up students' registration, on-line payment, generating reports for administration, track faculty teaching records, and checking lecturer and classroom availability for course scheduling $[26,27,29]$. In short, the demand for an integrated enterprise system to manage administrative tasks for universities continues to grow, for the purpose of efficient information management and streamlined data processing.

ERP use in HEIs integrates administrative functions that have been supported by separate legacy systems 3 in the past [28]. Separate legacy systems were "disparate" and have led to "duplicate resources and services" [28]. ERP enables HEIs to consolidate disparate data and legacy systems and adopt best-ofbreed processes and modern technology.

As different departments across an institution share an integrated database, end users can access data in real time.

According to [9], the main advantages of ERP in HEIs are (1) improved information access for planning and managing the institution, (2) improved services for the faculty, students and staff, (3) lower business risks, and (4) increased income and decreased expenses due to improved efficiency. [30] provide ERP benefits for universities in terms of business (integrated workflow, industry best practices, and reduced dependence on paper; improve internal communications; enhance strategic decision making and planning capabilities; reduce or eliminate manual processes...) and technical (access to data in real time; reduce or eliminate the need for backup or shadow systems; platform for re-engineering business practices and continued process improvements; increase data integrity, validity and reliability; develop and maintain consistent data definitions; assure system wide security and protection of confidential information ...)

In Morocco, we did not find work discussing the actual subject in Moroccan public universities.

\subsection{The ERP implementation process}

In order to better understand the process of ERP adoptions, a number of researchers have developed conceptual ERP life cycle frameworks or process models. [20] suggested a five-stage ERP implementation process using various reviews of the previous literature: project preparation, business blueprint, realization, final preparation, "Go-Live" and support.

Project preparation refers to a comprehensive planning phase that forms a project team with leadership roles, sets budget targets, and defines the project objectives and plan. In the business blueprint phase, the current business process is analyzed in detail in order to select an appropriate ERP system. A project team then is trained on functionality and configuration of the selected ERP system. An understanding of the selected ERP system allows a project team to gain insight to reengineering its business processes.

In the realization phase, a project team concentrates on implementing an ERP system including modification, development of interfaces, and data conversion. At the same time, each process design is tested on a conference room pilot 4 . In the final preparation phase, the entire process is fully integrated and tested throughout the organization with full data and various scenarios. End users are trained in this phase as well. Finally, in the "go-live" and support phase, the ERP system is constantly stabilized and may have extensions for competitive advantage.

\subsection{Challenges of ERP implementation in University context}

[31] suggest that ERP software, which incorporates best practices from the corporate business industry, is not appropriate for universities, since universities have unique structures and decision-making processes.

Organizational culture heavily affects ERP implementation. In [33] authors indicate that today's universities have been forced to admit that "education is a business and students are the customers". ERP implementation encourages universities take a more business-like approach to education, resulting in cultural changes including "the use of managerial language and techniques" [34]

There can be resistance to ERP implementation at universities because it involves not merely the adoption of a new information system, but a holistic change in organizational culture.

While there are diverse forms of management hierarchy from university to university, [35] describes that there exist two sources of authorities within a university: administrative authority and academic authority. ERP implementation is believed to reinforce administrative authority as a model of governance. For academics, this may lead to fear that use of a new system that results in increased transparency of their transactions would result in a loss of control. On the other hand, administrative staff may fear for their job security when redundant processes are eliminated work functions are automated across a university [35].

Moreover, [4] argue that ERP, as a "generic type of solution" from the corporate industry, could be a high-risk strategy for universities. Despite HEI's needs for unique business functions, ERP solutions limit their choices and encourage adopting a "generic solution".

Since there have been few discussions and considerations regarding the challenges that universities might face from generic ERP system adoption, there is little assurance that the process will be successful.

Also, as ERP systems are "large integrated packaged solutions" with dynamic complexity, it may cause difficulties with implementation for management and IT staff in universities, even those who might have comprehensive understanding of their own organizations [4]. This is because universities have expanded a range of systems many of which have sometimes competing functions whenever they had particular needs [4]. In the worst case, universities do not always have management or IT staff who are well-versed in organizational functions.

Standardization and integration, both of which are key features of ERP systems, limit flexibility in university systems. This loss of flexibility may lead staff to create 'workarounds' in which workers attempt to carry on their previous processes. This response to new ERP systems may ultimately increase staff workloads and create a data gaps between the system and reality.

\section{RESEARCH METHODOLOGY}

Given the purpose of this work that addresses the real difficulties of implementing ERP in public universities in Morocco, as well as the absence of an up-to-date Moroccan university to integrate ERP as an information system, a qualitative approach is needed to lead the exploratory case study Our own inclusion of issues and also a research hypothesis, which can form the basis of our empirical study [23].

In order to access to concrete situations in public university context, our choice examined the case method, insofar as the 
case method appears particularly suited to our research which has been little studied so far. The challenge of the case method is to give the opportunity to explore, understand or explain a composite reality of a dense content. Moreover, "the case studies are particularly recommended when addressing new and complex fields, where theoretical developments are weak and the resumption of the context is crucial for the development of understanding process" [24]. This corresponds to our exploration problem of a complex reality: understanding how and why in this situation is our main concern. Our research objective then is to produce the right representation of the observed reality.

There is no standard definition for the case study. We will define it as presented by [22,29], [25] and [29]. A case study examines a phenomenon in its natural setting, using multiple techniques such as data collection to gather information from one or several entities (individuals, groups or organizations). The method "Action Research" or "participatory research" used in this paper, which is a type of case studies, describes the studies in which the author, usually a researcher, is a participant in the implementation of the system [13]. Participatory research is based on the notion that the company must be experimentally understood through its major process of change such as the implementations of ERP. Three important factors must be considered: context, relational quality, and quality of the research itself $[14,36,37]$.

\section{FINDING AND RESULTS}

The case study which represents the purpose of this paper was conducted in four larges Moroccan public universities:

Our case study is a project to implement an ERP system for the first time within the 4 pilot universities of the ERP-MISSION project that was realized as part of the MISSION project: "Setting up a National Operational Information System Service "coordinated by the Hassan 1er University and involving all Moroccan public universities. This project is funded by the European Commission through the Executive Agency for Education, Audiovisual and Culture in the framework of the Tempus IV program for the period 2012-2015, which focuses on the development of higher education which is part of the European Union modernization program, and responding to the Moroccan priorities of structural measures (governance reform): Management, quality assurance and institutional and financial autonomy. It involved the Ministry of Higher Education, Scientific Research and Training of Moroccan Executives, the 12 Moroccan public universities, the National Instance of Evaluation, the University Agency of La Francophonie and Morocco Numeric Cluster. As well as European partners, namely: The University of Granada in Spain, the University of Coimbra in Portugal, the Royal Institute of Technology of Sweden and the University of Maine in France.

The main objective was the establishment of an ERP system with a structure of the Operational Information System in each Moroccan university partner. This system aims at the integration of the 4 building blocks support of the Moroccan university (Education, Finance, Heritage and Human Resources Management "GRH")

Each one of the 4 universities were designated as a leader in relation to a module of the modules chosen for the project.

I had the opportunity to work on these experiences which allowed me to conduct these projects as one of the main actors (Project Manager) during one year

In this study, several difficult situations were experienced with the various project teams. These situations vary according to the context, nature of business, the deadline and many other parameters. We list below the most important difficulties shared by this experience.

\subsection{Top management sponsor}

Having a sponsor is one of the key challenges that must be considered early in the implementation or extension of an ERP project. In the cases studied, the sponsor did not exist or exist but in a political way. Officially, the figure was not the sponsor of the ERP project. However, there is overall agreement that the then Vice-President acted in this project. One of its crucial functions is to act as an intermediary between the parts. This was a major challenge in the progress of the project, since it is the first experience of universities in the implement of this type of projects, as well as the lack of experience and does not allocate the Vice President of the University in this area, posed a great challenge with the project manager, which had a positive impact in the success of the project will also be addressed later.

\subsection{Project Management}

A successful implementation of ERP system requires an effective project management. Project management is the process of ongoing management of the implementation plan. It involves planning, allocating responsibilities, training, and determination of the success measures. Project management needs a steering committee which made up of senior management from different departments, project management, and the system end-users who should be involved in several phases of the ERP system lifecycle.

The project management should follow a clear methodology and appropriate management structure in order to achieve successful implementation of ERP project

The scope of the ERP implementation projects is among the main issues to be defined first. Indeed, it impacts directly the cost and time / deadline of overall implementation. This effect becomes more important if the scope changes in the implementation step.

\subsection{Project Champion}

A project champion is equivalent to a project leader, "who made a decisive contribution to the innovation by actively and enthusiastically promoting its progress through critical stages in order to obtain resources and/or active support from top management. A project champion is one of the key players during the process of adopting ERP system. If the development of an enterprise system is not carefully controlled by management, management may soon find itself under the control of the system". This highlights the importance of having a decision maker in the process of introducing and installing an ERP system.

\subsection{Resistance to change}

Implementing an ERP provides a structural change on all the company's bricks: operational, organizational, cultural, etc. Most project managers neglect the resistance to change part: either by ignorance or by advancing the Budget optimization pretext. However, this component may lead to project failure if not at least a loss of time and money as the final customer satisfaction was not successful.

\subsection{Cultural constraints affecting the calendar}

This is an important factor which is usually overlooked when assessing the overall project schedule for the ERP implementation. During the holy month of Ramadan, the number of hours worked decreased like the performance of the various teams: MOA, AMOA, MOE and AMOE. Holidays that coincide 
with religious celebrations, school holidays or summer vacation also have a strong impact on the efficiency of teams and consequently on the overall progress of the project.

\subsection{Teamwork \& Composition}

Teamwork \& Composition have been considered by many researchers and practitioners as one of the most critical success factor of ERP system implementation where all functional departments of the enterprise must be involved in the implementation process.

The success of the project relies on the skills and the knowledge of the project team members and on the experience of the project manager. Therefore, the selection of the project team members should be appropriate and carefully approached to pick the most skilled and knowledgeable staff with the right experienced manager. Forming the right project team by selecting the right members who deeply understand the business process and have long experience in the organization is crucial.

\subsection{Exploitation}

A special care must be taken into consideration at the selection phase of the ERP that best meets the business needs: major updates. The best illustration is that the editor requires a major upgrade version of the ERP every 5 years while the company sees no interest in this kind of update. The risk is the loss of the IT support and penalties payable in addition.

\section{CONCLUSION}

First of all, this article contributes to both the theory and practice by providing a comprehensive review of the ERP solution appearance to their evolution nowadays and their benefits, challenges and process implementation. Allowing us to confirm our problem explained previously, which is to identify the major difficulties and challenges encountered during the implementation of ERP in a Moroccan university context. Then we have justified the qualitative research method, motivated mainly by the Action Research rarity of this type of work and the relevance of the results through the experience. Finally, we have spread our case study through research efforts in four public Moroccan universities pilot in ERP-MISSION project, while detailing the significant challenges that have not conducted a total failure of implementation projects, but have actively contribute to a partial advantage of these types of projects.

Nevertheless, it is wise to mention that this study presents several limits, namely:

- The scarcity of this kind of research in the Moroccan context.

- The difficulty of extending the scope to cover another universities

- The Sensitivity of this kind of strategic projects which represents a crucial vector change in public Moroccans universities.

Finally, we propose some future research topics: study and address the download of integrated information systems projects by introducing a framework to implement ERP system; extending this study to other universities; comparing the results of this study with other Arab and African universities; and confirming these qualitative research results through quantitative research Other.

\section{ACKNOWLEDGMENTS}

Through this work, I thank all those who contributed to this courageous initiative in downloading the integrated information system through the ERP-MISSION project, who put confidence in the management of the project in an important and sensitive period of its progress. In the four universities.

\section{REFERENCES}

[1] Bidan M. 2004, «Fédération et Intégration des applications $\mathrm{du}$ Système d'information de Gestion ", Systèmes d'Information et Management, $\mathrm{N}^{\circ} 2$, Vol.9, pp. 1-20.

[2] Wong, A., Scarbrough, H., Chau, P., \& Davison, R. (2005). Criticalfailurefactors in ERP implementation.

[3] https://www.csefrs.ma/wp-content/uploads/2017/02/Re-sume---ENF-ANG.pdf

[4] Pollock, N. and Cornford, J. (2004), "ERP Systems and the University as a "unique" organisation", Information Technology and People, (17:1), pp. 31.52.

[5] CIMSI 2014, RAZIK Mohamed, RADI Bouchaib, OKAR Chafik «Les facteurs clés de succès pour l'amélioration de la performance de la fonction entreposage au sein des entreprises marocaines ».

[6] Mandal, P., \&Gunasekaran, A. (2003). Issues in implementing ERP: a case study. European Journal of Operational Research, 146(2), 274-283.

[7] James J. Duderstadt, Daniel E. Atkins, Douglas Van Houweling. Higher Education in the Digital Age: Technology Issues and Strategies for American Colleges and Universities (ACE/Praeger Series on Higher Education) Hardcover - December 30, 2002.

[8] Lockwood, G. (1985). Universities as organizations. In G. Lockwood, and J. Davies (Eds.), Universities: The Management Challenge (pp. 139-163). Windsor, UK: NFERNelson Publishing.

[9] King, P., R. Kvavik and John,V.(2002). "Enterprise Resource Planning Systems in Higher Education." EDUCAUSE 22: 1-5.

[10] Ahed Abugabah, Louis Sanzogni. Enterprise Resource Planning (ERP) System in Higher Education: A literature Review and Implications. International Journal of Social, Behavioral, Educational, Economic, Business and Industrial Engineering Vol:4, No:11, 2010

[11] Martin, M., 1998. Enterprise resource planning. Fortune 137(2), 149-151

[12] Elragal, A. \& Al-Serafi, A. (2011). The effect of ERP system implementation on business performance: An exploratory case-study. Communications of the IBIMA, pp. 1- 19

[13] Ken Laudon, Jane Laudon. Management Information Systems: International Edition. Publisher: Pearson Higher Education Copyright: 2010 Format: Paper; 672 pp

[14] C Ranganathan, CV Brown. ERP investments and the market value of firms: Toward an understanding of influential ERP project variables Information Systems Research, 2006 - pubsonline.informs.org

[15] Pliskin, N., Zarotski, M., 2000. Big-Bang ERP implementation at a global company. Annals of Cases on Information Technology Applications and Management Organizations 2, 233-248

[16] Laughlin, S.P., 1999. An ERP game plan. Journal of Business Strategy 20 (1), 32-37. 
[17] ROBERT REIX, BERNARD FALLERY, MICHEL KALIKA, FRANTZ ROWE. SYSTÈMES D'INFORMATION ET MANAGEMENT, 7ÈME ÉDITION. http://www.vuibert.fr/ouvrage/9782311012354systemes-d-information-et-management

[18] Prasad Bingi , Maneesh K. Sharma \& Jayanth K. Godla (1999) CriticalIssues Affecting an ERP Implementation, Information Systems Management, 16:3, 7-14,

[19] Ehie and Madsen, 2005 Ehie, I.C. \& Madsen, M., 2005. Identifying critical issues in Enterprise Resource Planning (ERP) implementation. Computers in Industry, Volume 56, pp. 545-557.

[20] Zhenyu Huang, Prashant Palvia. ERP Implementation Issues in Advanced and Developing Countries. August 2001Business Process Management Journal 7(3):276-284 DOI: $10.1108 / 14637150110392773$

[21] Bancroft, N., Seip, H., Sprengel, A., 1998. Implementing SAP R/3: How to introduce a large system into a large organization. Manning Publications, Greenwich, CT, USA

[22] Benbasat, I. "An Analysis of Research Methodologies," in The Information Systems Research Challenge, F. Warren McFarlan (ed.), Harvard Business School Press, Boston, Massachusetts1, 984, pp.47-85.

[23] Bonoma, T.V."Case Research in Marketing:Opportunities, Problems, and a Process," Journal of Marketing Research, Volume 22, Number 2, May 1985, pp. 199-208.

[24] Jose EstevesJ Pastor. Enterprise Resource Planning Systems Research: An Annotated Bibliography. January 2001Communications of the Association for Information Systems 7(8):1-52 DOI: 10.17705/1CAIS.00708

[25] Kaplan, R.S. "The Role of Empirical Research in Management Accounting," Working Paper 9-785-001, Division of Research, Harvard Business School, Boston, Massachusetts, 1985.

[26] Stone, E. ResearchMethodsin Organizational Behavior, Scott, Foresman and Company, Glenview, Illinois, 1978.

[27] Huang, Z., \&Palvia, P. (2001). ERP implementation issues in advanced and developing countries. Business Process Management Journal, 7(3), 276-284.

[28] Brahim Bighrissen, El Mehdi Ettamiri et Chihab Cherkaoui (2012). «Towards the Success of ERP Systems :Case Study in Two Moroccan Companies ». Journal of Enterprise Resource Planning Studies, Vol. 2012 (2012), Article ID 731113, 17 pages, DOI: 10.5171/2012.731113.

[29] El Abbassi, A., \& Chafik, K. (2014). The Decision to Invest in Information Systems: Case of Adopting ERP in the Moroccan Public Largest Companies.International Journal of Computer Applications, 88(15), 49-54

[30] Gheorghe Sabau, Mihaela Munten, Ana-Ramona Bologa, Razvan Bologa, Trăian Surcel less. An evaluation framework for higher education ERP systems. Published 2009.

[31] Heiskanen, A., Newman, M. and Similä, J. (2000)."The Social Dynamics of Software Development". Accounting, Management and Information Technologies, Vol. 10, No 1 , pp. 1-32.

[32] Coghlan, D., \&Brannick, T. (2014). Doing action research in your own organization.Sage.

[33] Koch, C., Slater, D., \&Baatz, E. (1999). The ABCs of ERP.CIO magazine, 22.

[34] David Allen, Thomas Kern, Mark Havenhand. ERP Critical Success Factors: An Exploration of the Contextual Factors in Public Sector Institutions January 2002 DOI: 10.1109/HICSS.2002.994295.

[35] Klaus, H., Rosemann, M., \& Gable, G. G. (2000). What is ERP?.Information systems frontiers, 2(2), 141-162.

[36] D. L. Olson, et al., "Relative impact of different ERP forms on manufacturing organisations: an exploratory analysis of a global manufacturing survey," International Journal of Production Research, vol. 51, pp. 1520-1534, 2013.

[37] Reix R., Fallery B., Kalika M. et Rowe F., " Systèmes d'information et management des organisations », 6ème édition., Vuibert. 2011. 